\title{
Genetic trends in the performance and reproductive traits of pigs
}

\author{
Rodolpho de Almeida Torres Filho ${ }^{1}$, Robledo de Almeida Torres ${ }^{1}$, Paulo Sávio Lopes ${ }^{1}$, Carmen Silva \\ Pereira $^{1}$, Ricardo Frederico Euclydes ${ }^{1}$, Cláudio Vieira de Araújo ${ }^{1}$ and Martinho de Almeida e Silva ${ }^{2}$ \\ ${ }^{1}$ Universidade Federal de Viçosa, Departamento de Zootecnia, Viçosa, Minas Gerais, Brazil. \\ ${ }^{2}$ Universidade Federal de Minas Gerais, Departamento de Zootecnia da Escola de Veterinária, Belo \\ Horizonte, Minas Gerais, Brazil.
}

\begin{abstract}
The selection and evaluation of breeds and purebred lines to be used as the parental stock is an important step for the success of any animal breeding program. In this study, the feed:gain ratio, backfat thickness corrected for $100 \mathrm{~kg}$, age to $100 \mathrm{~kg}$, average daily gain, and age of sow at first farrowing were used to evaluate the genetic trends for direct and maternal additive genetic values in Large White pigs. The total number of piglets born or born alive and the litter weight at birth were used as indicators of the genetic trends for the direct additive values. The genetic trends were calculated by regression of the average predicted genetic values per year for each trait versus the offspring's year of birth (for performance traits) or versus the dam year of birth (for reproduction traits). The genetic trend estimates for direct effects showed that selection decisions made during the breeding program effectively improved the performance traits. However, for reproductive traits, the regression estimates showed no definite trend. The genetic trends for the maternal effects were generally positive but of low magnitude.
\end{abstract}

Key words: average daily gain, backfat thickness, birth litter weight.

Received: April 30, 2003; Accepted: October 24, 2003.

\section{Introduction}

The use of breeds and purebred lines in efficient crossbreeding programs depends on the availability of improved genotypes to achieve good results. For this reason, the selection and evaluation of breeds and purebred lines that are to be used is an important step for the success of any animal breeding program.

An estimate of the genetic progress achieved by selection programs is necessary in order to describe the genetic changes progress, to assess the benefits of the selection program and to introduce necessary adjustments (Euclides Filho et al., 1997). Hill (1972a,b) proposed the use of a control group and the adoption of divergent selection to remove any environmental influence. However, the high cost of maintaining a control population makes these two procedures unfeasible for commercially oriented breeding programs. In a study using a control line and a selected line, Blair and Pollak (1984) used three approaches to estimate the genetic superiority of the selected line: 1) deviation of the predicted annual phenotype mean of the selected line compared to the predicted annual phenotype

Send correspondence to Robledo de Almeida Torres. Universidade Federal de Viçosa, Departamento de Zootecnia, Av. PH Rolfs s/n, 36571-000, Viçosa, Minas Gerais, Brazil. E-mail: rtorres@ufv.br. mean of the control line, 2) deviation of the predicted annual phenotype mean of the selected line compared to the estimated year effect based on the control line records, and 3) yearly means of the predicted breeding values of the selected line. Method 3 depended on the heritability and produced better partitioning of the phenotype trend in the genetic and environmental components. The results of this study indicated that this type of analysis could be used to estimate genetic trends, particularly in commercial breeding herds for which it was impossible to establish and maintain control lines.

Using simulated data, Sorensen and Kennedy (1984) demonstrated that, under specific conditions, the mixed models equations do not require the use of a control population to appropriately partition the phenotype trend into environmental and genetic components. According to these authors, if the variances of the traits are known before selection and if the selection is based on a linear function of the data and the relationship matrix is complete, then the genetic trend can be estimated using a mixed models approach.

The aim of this study was to evaluate the genetic trends of the direct and maternal additive genetic values for performance and reproductive traits in pigs. 


\section{Material and Methods}

The data used in this study were collected from 1993 to 1999 from a Large White purebred pig line maintained by the breeding program of the Sadia S.A. meat company in the southern Brazilian state of Santa Catarina.

The animals were all from a single farm. The piglets were maintained in collective pens until they were 12 weeks of age, when they underwent their first individual performance test to determine the feed:gain ratio. The average daily gain was monitored in males until they reached a live weight (LW) close to $100 \mathrm{~kg}$. For the females, the test was done in collective pens so that only the average daily gain was determined. At the end of the test, backfat thickness was measured in all of the animals.

Performance traits were evaluated in each sex since the form of management differed for males and females. In males, feed:gain ratio (FG-M), backfat thickness corrected for $100 \mathrm{~kg} \mathrm{LW}$ (BFT-M), age to $100 \mathrm{~kg} \mathrm{LW} \mathrm{(AGE-M)} \mathrm{and}$ average daily gain (ADG-M) were monitored throughout the test. In females, backfat thickness corrected for $100 \mathrm{~kg}$ LW (BFT-F), age to $100 \mathrm{~kg} \mathrm{LW} \mathrm{(AGE-F)} \mathrm{and} \mathrm{average} \mathrm{daily}$ gain (ADG-F) were monitored from birth to the end of the test. Backfat thickness was adjusted for $100 \mathrm{~kg}$ using correction factors provided by the company. The reproductive traits evaluated were: age of dam at first farrowing (DAFF), total number of piglets born (NPB), total number of piglets born alive (NPBA) and birth litter weight (BLW).

The data were grouped in four files. The first file contained pedigree information (18,279 records), the second, male performance $(7,009$ records $)$, the third, female performance (10,541 records), and the forth, reproductive information (3,937 records). The genetic parameters were estimated by the Restricted Maximum Likelihood (REML) method using the Multiple Trait Derivative-Free Restricted Maximum Likelihood (MTDFREML) program described by Boldman et al. (1995).

According to Torres Filho et al. (2004), the most suitable model for evaluating the performance traits and DAFF includes the direct genetic effect of the animal, the maternal effect and the litter common effect. For litter traits, the most suitable model includes only the direct genetic effect of the animal. Thus, two different models were used in the analyses: model 1 for the performance traits and DAFF and model 2 for the litter traits, as follows:

$$
\text { Model 1: } \vec{y}=X \vec{b}+Z_{1} \vec{a}+Z_{2} \vec{m}+Z_{3} \vec{p}+\vec{e},
$$

where $\operatorname{Var}(\mathrm{a})=\mathrm{A} \sigma_{a}^{2}, \operatorname{Var}(\mathrm{m})=\mathrm{A} \sigma_{m}^{2}, \operatorname{Cov}(\mathrm{a}, \mathrm{m})=\mathrm{A} \sigma_{a m}^{2}$ and $\operatorname{Var}(\mathrm{p})=\mathrm{I} \sigma_{P}^{2}$

Model 2: $\vec{y}=X \vec{b}+Z_{1} \vec{a}+\vec{e}$,

where $\operatorname{Var}(\mathrm{a})=\mathrm{A} \sigma_{a}^{2}, \vec{y}$ is the vector of the observations, $\vec{b}$ is the vector of the fixed effects of the contemporary groups and the covariables, $\vec{a}$ is the vector of the direct additive ge- netic effects, $\vec{m}$ is the vector of the maternal additive genetic effects, $\vec{p}$ is the vector of the litter common effects, $\vec{e}$ is the vector of the residual effects, $X, Z_{1} Z_{2}$ and $Z_{3}$ are the incidence matrices for the fixed, direct additive genetic, maternal additive genetic and litter common effects, respectively, $\sigma_{a}^{2}$ is the variance attributed to the direct genetic effects, $\sigma_{m}^{2}$ is the variance attributed to the maternal genetic effects, $\sigma_{a m}^{2}$ is the covariance between the direct and maternal genetic effects, $\sigma_{P}^{2}$ is the variance of the litter common effects, A is the Wright's numerator relationship matrix and I is the identity matrix.

Contemporary groups were formed by combining the period, based on the week of the year, with the year. The periods were defined as follows: period $1=$ from the $48^{\text {th }}$ week to the $8^{\text {th }}$ of the following year, period $2=$ from the $9^{\text {th }}$ week to the $21^{\text {th }}$, period $3=$ from the $22^{\text {th }}$ to the $34^{\text {th }}$, and period $4=$ from the $35^{\text {th }}$ week to the $47^{\text {th }}$. The week and the year of farrowing were considered in the file containing reproductive information, and the week and year of birth in the other files. The linear and quadratic effects of age of dam at farrowing were included in the model for total NPB, total NPBA and BLW.

The genetic trends for the direct and maternal additive genetic values were calculated by regression of average predicted breeding values for the traits versus the animal's birth year (in the case of performance traits) and versus the dam's birth year (in the case of the reproductive traits).

\section{Results}

The estimates of the genetic trends for the direct additive genetic effects and their standard errors and coefficients of determination $\left(\mathrm{R}^{2}\right)$ are shown in Table 1. For performance traits, the direct additive genetic values for males and females showed similar trends, except for ADG. The regression equations were significant and the coefficients of determination $\left(\mathrm{R}^{2}\right)$ were relatively high, except for ADG-F, for which the regression equation was not significant and $\mathrm{R}^{2}$ was lower $(0.07)$, indicating that in this trait there was no definite genetic trend. Figures 1-4 summarize the genetic trends for a direct effect on the performance traits.

The genetic trends for FG, AGE and BFT were negative (favorable) while those for ADG were positive (also favorable), which reflected the aim of the company's breeding programs, i.e., a decrease in FG, AGE, and BFT and an increase in ADG of male and female pigs. For the reproductive traits, the regression equations were not significant and there were coefficients of determination lower than 0.30 , indicating that genetic trends were not welldefined for those traits. The genetic trends for the maternal additive genetic values, their standard errors, coefficients of determination and significance levels are shown in Table 2 . The maternal genetic trends were generally positive but 
Table 1 - Genetic trend estimates $(\hat{b})$ and respective standard errors $(\mathrm{s}(\hat{b}))$, coefficients of determination $\left(\mathrm{R}^{2}\right)$, and probability values (PV) for the direct additive genetic effect.

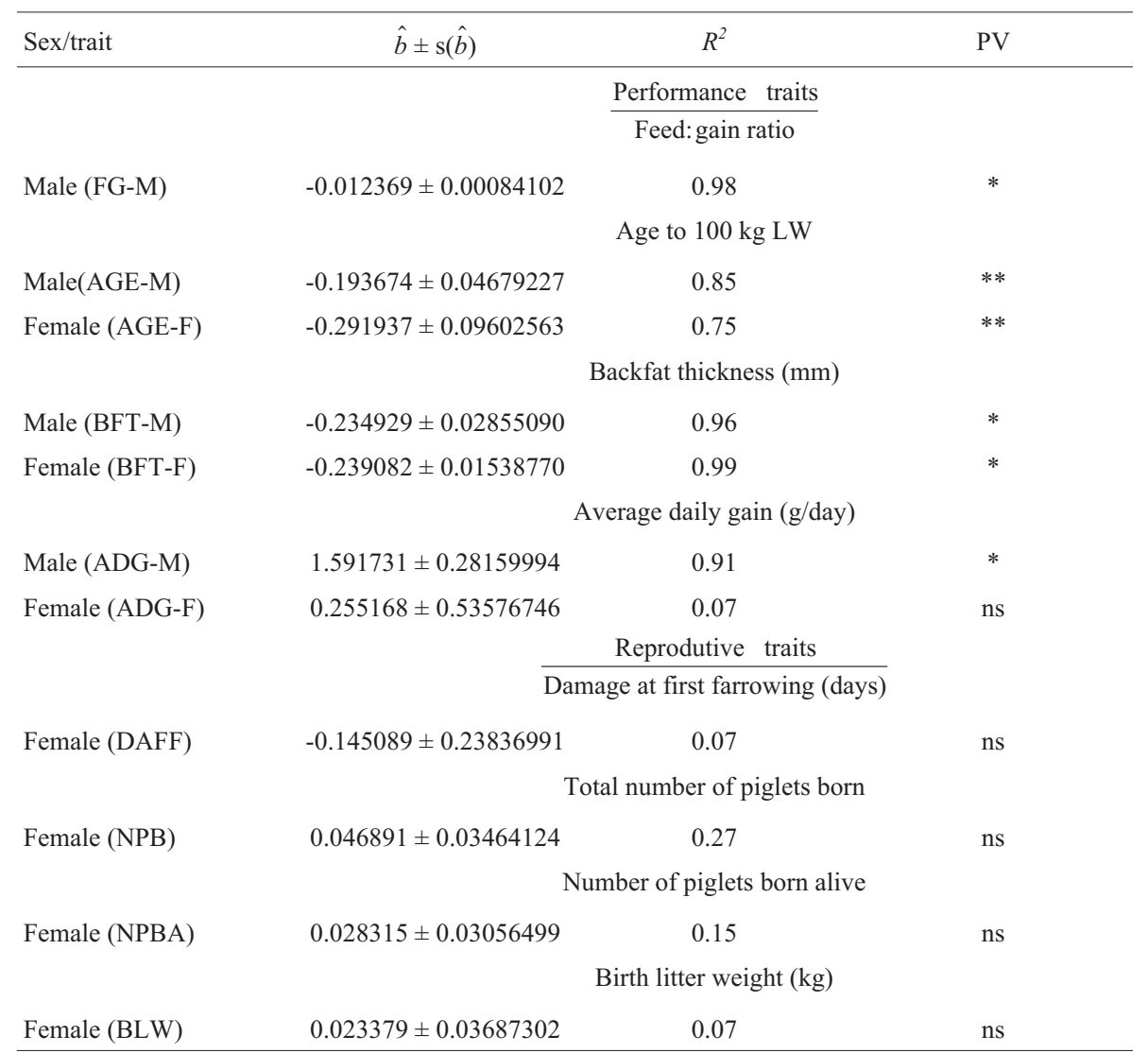

LW - live weight $* \mathrm{p}<0.01,{ }^{*} \mathrm{p}<0.05$, ns - not significant.

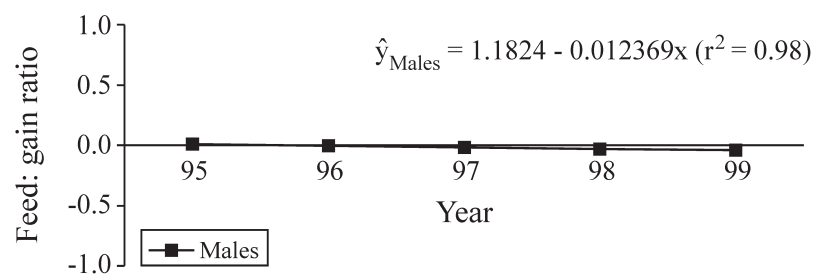

Figure 1 - Direct genetic trends for the feed:gain ratio from 1995 to 1999.

of low magnitude. This was expected since the heritability estimates for this effect were low (Torres Filho, 2001) and not much attention was given to maternal effects in these programs.

\section{Discussion}

Our results showed that there were differences in the genetic trends for the direct additive ADG values in males and females since this trait was evaluated in different periods according to the animals' sex: females were evaluated from birth to the end of test whereas males were evaluated from 12 weeks of age up to the end of test. The genetic progress estimated for ADG in males was $1.59 \mathrm{~g} /$ day/year, lower than that one reported by Costa (1999) for Large

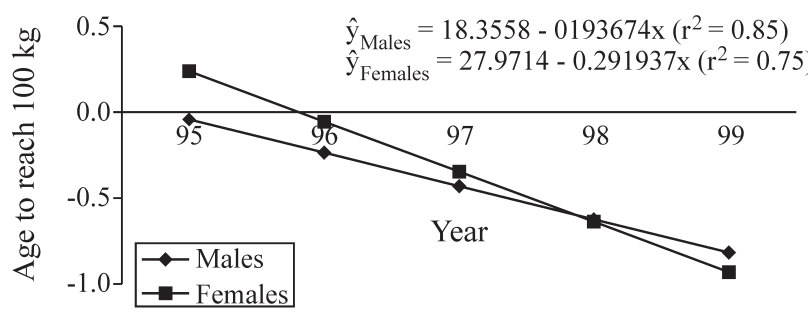

Figure 2 - Direct genetic trends for age to $100 \mathrm{~kg}$ from 1995 to 1999.

White pigs and higher than that reported by Paneto (1998, cited by Pita, 2000) in an elite herd of the same breed.

The genetic trends estimates of $-0.19 \pm 0.04$ and $-0.29 \pm 0.09$ day/year for AGE in males and females, respectively, were lower than for the age to reach a definite weight reported by Pita (2000) (-0.54 day/year) and by Hudson and Kennedy (1985) (-0.90 day/year) for different lines of Large White breed. Chen et al. (2002) reported genetic trends estimates for days to reach $113.5 \mathrm{~kg}$ of -0.41 , $-0.54,-0.13$ and -0.52 for Large White, Duroc, Hampshire and Landrace pigs, respectively; the estimate for Hampshire was lower than that one calculated here, but higher than for the other breeds. 


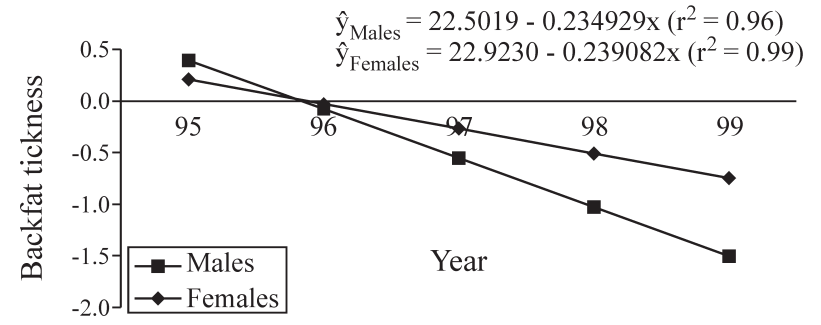

Figure 3 - Direct genetic trends for backfat tickness (mm) from 1995 to 1999.

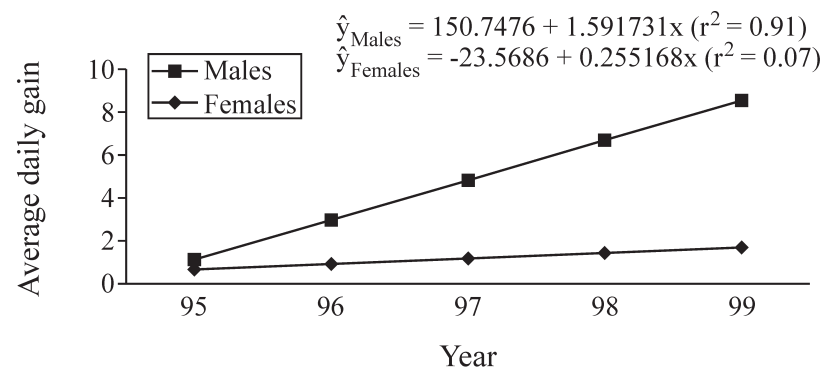

Figure 4 - Direct genetic trends for average daily weight gain (g) from 1995 to 1999.

The estimated annual genetic trend of $-0.23 \pm$ $0.03 \mathrm{~mm} /$ year for BFT was lower than the value of $-0.50 \pm$ $0.03 \mathrm{~mm}$ described by Costa (1999), and lower than the $-0.45,-0.43,-0,31$ and -0.37 for Large White, Duroc, Hampshire and Landrace pigs reported by Chen et al. (2002).
Despite favorable genetic trends for the performance traits, the magnitudes were generally lower than those reported in the literature. The Large White line has been undergoing selection for many generations and may have reached a high level of genetic improvement. Thus, for example, the line used here had a BFT of 10.23 and $10.57 \mathrm{~mm}$ for males and females, respectively, an ADG of $1056.45 \mathrm{~g}$ for males, and an AGE of 140.37 for males and 154.16 for females. Compared with the averages of $858.83 \mathrm{~g}$ and $16.5 \mathrm{~mm}$ for ADG and BFT, respectively, of a Large White line studied by Costa (1999), and with averages of 149.05 days for age at the end of test, standardized for $95 \mathrm{~kg}$, $14.85 \mathrm{~mm}$ for BFT, and $910 \mathrm{~g}$ for ADG in a Large White line evaluated by Pita (2000), the line used showed better performance than those ones with higher genetic trend estimates.

In contrast to the performance traits, direct additive genetic values for reproductive traits showed no definite trend, which agrees with Chen et al. (2003b), Pires (1999) and Irgang et al. (1997) who observed very little genetic progress in reproductive traits of pigs. The low degree of genetic progress for the reproductive traits can be explained mainly by two factors. First, in this selection program greater emphasis was placed on performance traits than on reproductive traits. Second, these traits generally have a low heritability and this may slow down genetic progress. Chen et al. (2003b) argued that the low rates of genetic trends were because breeders were not selecting them or that the selection applied was ineffective because of heritabilities. Based on a study of the reproductive traits of lines selected for performance traits, Kerr and Cameron

Table 2 - Genetic trend estimates $(\hat{b})$ and respective standard errors $(\mathrm{s}(\hat{b}))$, coefficients of determination $\left(\mathrm{R}^{2}\right)$ and probability values $(\mathrm{PV})$ for the maternal additive genetic effect.

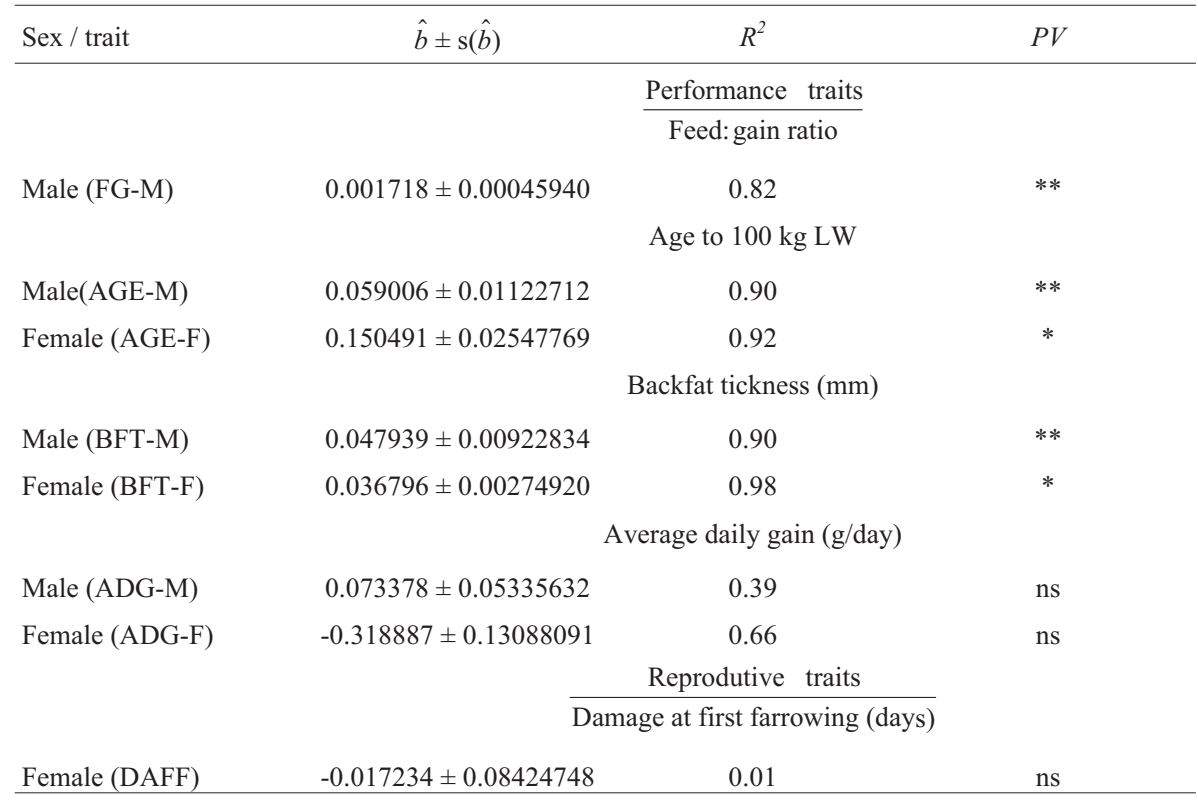

LW - live weight. ${ }^{*} \mathrm{p}<0.01, * * \mathrm{p}<0.05$. ns- not significant. 
(1995) pointed out that the estimates of genetic parameters could be biased for reproductive traits when measured in females selected based on other performance traits.

Significant progress was achieved in the performance traits of the line studied, while no significant alterations occurred in the reproductive traits. Fredeen and Mikami (1986) examined the correlated changes in female reproductive traits in lines selected for increased growth rate and decreased fat. These authors used the records of reproductive traits of three lines selected for nine generations, one for maximum growth rate, another for minimum BFT, and one for an index that combined the two traits. A comparison of these lines to a control population showed that reproductive traits were improved in the selection programs for growth rate and carcass merit. Based on an evaluation of performance index (growth rate and fat) in approximately nine generations of divergent selection, Vangen (1980) reported a positive trend in litter size and litter weight in a line of high performance, and a significant negative trend for these traits in low performance lines. Gray et al. (1965) found no change in litter size or litter weight during five generations of selection for low fat, whereas Berruecos et al. (1970), in a similar study, reported a significant decline in litter size and litter weight. The results obtained here agree obtained agree with those of Gray et al. (1965).

Chen et al. (2001) reported that selection for lean growth traits was effective and should have little effect on litter traits in a synthetic line of Large White-Meishan pigs. Noguera et al. (2002), in an evaluation of the results of experimental selection for increased litter size in a Landrace pig population, reported that selection was effective and that none of the genetic responses was correlated with growth and backfat thickness. Chen et al. (2003a) reported that when the lean growth trait was included in a maternal-trait evaluation using a multiple-trait model, accuracy of the genetic evaluation for litter traits was increased.

Kerr and Cameron (1995) showed that a correlated response in reproductive traits with selection for efficiency components and growth rate depended on the selection strategy. Thus, evaluations of alternative selection strategies should include predictions of the correlated response in reproductive traits based on unbiased estimates of the genetic parameters. The information in the present study was based on the Large White breed, which is frequently used as a female line in breeding programs. Thus, a knowledge of the selection impacts on the direct additive genetic effects of performance and reproductive traits is essential for future planning of the selection program.

For the maternal additive genetic effects considered, the trends were significantly positive for FG, AGE, and BFT, but were of low magnitude. Chen et al. (2002) studied the genetic tendency of age to $113.5 \mathrm{~kg}$ and backfat adjusted for $113.5 \mathrm{~kg}$ in Large White, Duroc, Hampshire and Landrace pigs, and obtained lower estimates of maternal genetic that ranged from 0.01 to 0.05 ; the genetic trends for this effect were not reported. Pires (1999) also reported low estimates for a trend of maternal effect on reproductive traits. According to this author, one factor that could explain low, null or negative estimates of genetic trends for maternal effects is the antagonism between the direct and maternal effects since, when selection is based only on direct additive genetic effects, maternal ability tends to decrease.

Despite the low magnitude of the maternal genetic trends, and based on the likelihood ratio test reported by Torres Filho et al. (2003) for this same data set, the inclusion of the maternal effect was significant for the traits considered here. This finding indicates that unbiased estimates of the genetic parameters can only be obtained with a model that includes this effect. Based on an analysis of traits measured during a post-weaning performance test in four breeds of pigs, Johnson et al. (2002) concluded if the maternal effect was important, then it would had to be included in genetic evaluation systems in order to obtain unbiased estimates of direct breeding values; a similar argument applied if the estimates of maternal effects were low. Since the population used here was a female line, maternal ability is an important trait in its evaluation.

In conclusion, genetic trends estimates for the direct additive genetic values indicated that the current selection program has been achieving favorable results. However, the estimates of genetic progress showed that the trends for reproductive traits were not as well-defined as those for performance traits since they were lower in magnitude than the latter.

\section{Acknowledgments}

The authors thank the meat company Sadia S.A. for providing data essential for this work. This study was supported by the Conselho Nacional de Desenvolvimento Científico e Tecnológico (CNPq).

\section{References}

Berruecos JM, Dillard EV and Robinson OW (1970) Selection for low backfat thickness in swine. J Anim Sci 30:844.

Blair HT and Pollak EJ (1984) Estimation of genetic trend in a selection population with and without the use of a control population. J Anim Sc 58:878-886.

Boldman KG, Kriese LA, Van Vleck LD and Kachman SD (1995) A manual for use of MTDFREML, a set of programs to obtain estimates of variances and covariances [DRAFT]. U.S. Department of Agriculture/Agriculture Research Service, Lincoln, 115 pp.

Chen P, Baas JC, Dekkers JCM and Christian LL (2001) Selection for lean growth rate correlated response in litter traits in a synthetic line of Yorkshire-Meishan pigs. Can J Anim Sc 81:205-214

Chen P, Baas TJ, Mabry JW, Dekkers JCM and Koelher KJ (2002) Genetic parameters and trends for lean growth rate and its components in U.S. Yorksire, Duroc, Hampshire and Landrace pigs. J Anim Sci 80:2062-2070. 
Chen P, Baas TJ, Mabry JW and Koelher KJ (2003a) Genetic correlation between lean growth and litter traits in U.S. Yorkshire, Duroc, Hampshire, and Landrace pigs. J Anim Sci 81:1700-1705.

Chen P, Baas TJ, Mabry JW, Koelher KJ and Dekkers JCM (2003b) Genetic parameters and trends for litter traits in U.S. Yorkshire, Duroc, Hampshire, and Landrace pigs. J Anim Sci 81:46-53.

Costa ARC (1999) Avaliação genética e valores econômicos de características de desempenho em suínos, MSc Dissertation, Universidade Federal de Viçosa, Viçosa.

Euclides Filho K, Silva LOC, Alves RGO and Nobre PRC (1997) Tendências genéticas na raça Indubrasil. XXXIV Reunião Anual da Sociedade Brasileira de Zootecnia. Juiz de Fora, Brasil, pp 171-172.

Fredeen, HT and Mikami, H (1986) Mass selection in a pig population: correlated responses in reproductive performance. $\mathrm{J}$ Anim Sci 62:1532-1532.

Gray RC, Tribble LF, Day BN and Lasley JF (1965) Five generations of selection for thinner backfat. J Anim Sci 24:848.

Hill WG (1972a) Estimation of realized heritabilities from selection experiments. I. Selection in one direction. Biometrics 28:767-780.

Hill WG (1972b) Estimation of realized heritabilities from selection experiments. II. Divergent selection. Biometrics 28:747-765.

Hudson GFS and Kennedy BW (1985) Genetic evaluation of swine for growth rate and backfat thickness. J Anim Sci 61:83-91.

Irgang R, Fávero JA and Medeiros G (1997) Tendências fenotípicas e genéticas do número de leitões nascidos vivos em porcas Landrace e Large White. Anais da Reunião Anual da Sociedade Brasileira de Zootecnia, Juiz de Fora, Brazil, pp 320-323.
Johnson ZB, Chewning JJ and Nugent III RA (2002) Maternal effects on traits measured during postweaning performance test of swine from four breeds. J Anim Sci 80:1470-1477.

Kerr JC and Cameron ND (1995) Reproductive performance of pigs selected for components of efficient lean growth. Anim Sci 60:281-290.

Noguera JL, Varona L, Dabot D and Estany J (2002) Multivariate analysis of litter size for multiple parities with production traits in pigs: II. Response to selection for litter size and correlated response to production traits. J Anim Sci 80:25482555.

Pires AV (1999) Avaliação genética de características reprodutivas em suínos. MSc Dissertation, Universidade Federal de Viçosa, Viçosa.

Pita FVC (2000) Modelos para avaliação genética e comparação de caracteríticas de desempenho para a seleção de suínos. MSc Dissertation, Universidade Estadual Paulista, Jaboticabal, SP.

Torres Filho RA (2001) Avaliação genética de características de desempenho e reprodutivas em suínos. MSc Dissertation, Universidade Federal de Viçosa, Viçosa.

Torres Filho RA, Torres RA, Lopes PS, Euclydes RF, Araújo CV, Pereira CS and Silva MA (2004) Avaliação de modelos para estimação de componentes de (co)variância em características de desempenho e reprodutivas em suínos. Rev Bras Zootec 33:350-357.

Sorensen DA and Kennedy BW (1984) Estimation of response to selection using least-squares and mixed model methodology. J Anim Sci 58:1097-106.

Vangen O (1980) Studies on a two trait selection experiment in pigs. VI Heritability estimates of reproductive traits. Influence of maternal effects. Acta Agric Scand 30:320.

Associate Editor: Pedro Franklin Barbosa 